\title{
Physical characteristics and ventilatory function of 404 commercial divers working in the North Sea
}

\author{
W. A. CROSBIE AND M. B. CLARKE \\ From the Chest Unit, Kings College Hospital Medical School, and the Department of Medical Physics, \\ Kings College Hospital, London SE5 \\ R. A. F. COX, N. K. I. MCIVER, I. K. ANDERSON, H. A. EVANS, G. C. LIDDLE, \\ J. L. COWAN, C. H. BROOKINGS, AND D. G. WATSON
}

From the North Sea Medical Centre, Gorleston-on-Sea, Great Yarmouth, Norfolk

ABSTRACT The physical characteristics and simple lung ventilatory indices (FVC, FEV , $\mathrm{FEV}_{1} / \mathrm{FVC}$ ) of 404 commercial divers employed by companies operating in the North Sea were analysed. These findings were correlated with the diving experience and maximum operating depth of each diver. All the divers were men of average height $176.9 \mathrm{~cm}$, and weight $77 \cdot 1 \mathrm{~kg}$ which is greater than average for active Western males, but only $6 \%$ were more than $120 \%$ of their predicted weight. The average duration of commercial diving was $7 \cdot 1$ years, $11 \%$ of divers having less than one year's experience. Sixty-seven per cent had worked at a maximum depth of $200 \mathrm{ft}(61 \mathrm{~m})$ and only $6 \%$ had worked deeper than $500 \mathrm{ft}(153 \mathrm{~m})$. The mean forced vital capacity (FVC) was $120.4 \%$ of the predicted value which indicated that they could voluntarily move large amounts of gas in and out of their lungs. This was greatest in the divers who went deepest. The mean forced expired volume in one second $\left(\mathrm{FEV}_{1}\right)$ was $117 \%$ of the predicted value showing that expiratory airflow capacity was also increased, but to a lesser extent than the FVC. The mean FEV 1 FVC ratio was normal but in $16 \%$ of the divers it was less than $75 \%$ which might indicate early expiratory airflow obstruction. This finding was related to age, and not to undersea environmental factors. These results show that commercial divers form an experienced, physically fit group of men who have large lung capacities advantageous to their occupation. Moving gas of increased density in and out of their lungs may well have hypertrophied the muscles of respiration.

The urgent need to develop the oil resources under the North Sea has produced considerable demand for commercial divers. A recent report by the Scottish Council of the British Medical Association (1975) has drawn attention to the lack of accessible information on the physical characteristics and pulmonary function of these men. The report also confirms the dangerous nature of the work where the fatality rate is approximately 100 per 1000 employed each year, a level 33 times that of coalmining.

Diving regulations require that commercial divers be medically examined within 12 months before diving and annually thereafter or after an illness lasting more than seven consecutive days. Restric-

Received for publication 16 February 1976 Accepted for publication 12 August 1976 tions may then be imposed which limit the operational scope of the individual. The application of these regulations has been left to private arrangements between divers, diving companies, and medical practitioners many of whom work in areas close to offshore service ports. Such a service has been provided during the past 10 years by a group of general practitioners centred at Great Yarmouth (British Medical Journal, 1976).

Considerable medical knowledge about commercial divers has been accumulated including tests of ventilatory lung function. This paper aims to describe the physical characteristics of these divers and their voluntary lung volumes, and to correlate these findings with the individual diving histories in order to find out some of the effects on the lungs of working underwater. 


\section{Methods}

The age of each diver was noted and his height (in $\mathrm{cm}$ ) and weight (in $\mathrm{kg}$ ) (without shoes and jacket) were measured. The medical history, physical examination, chest radiograph, and electrocardiograph were recorded and any clinical abnormality investigated before the individual was declared fit to dive. Weight was compared with predicted values (Documenta Geigy, 1970) but no allowance was made for shoes. Height was compared with values for physically active males in the United Kingdom (Montegriffo, 1968). Surface area was calculated from the formula of Dubois and Dubois (1915). Forced vital capacity (FVC) was assumed to be the same as the vital capacity and the predicted value of this measurement and the forced expired volume in one second $\left(\mathrm{FEV}_{1}\right)$ were taken from Kory et al. (1961).

The diving experience of each man was known from his commercial record and only information from this source was used. Hence the number of years of employment as a commercial diver, the maximum recorded depth of dive, and the longest time he had worked at this depth on any single occasion was known. The specific operational levels selected for grouping our divers were based on two factors. Divers can work to a depth of $200 \mathrm{ft}(61 \mathrm{~m})$ breathing air but below this depth they must use an oxygen/inert gas mixture. Since 1974 new regulations limit the depth to $50 \mathrm{~m}$ using natural compressed air, but some of the dives we included took place before these regulations came into force. The divers could therefore be divided into those who had only used air and those who had also used the gas mixture. The other levels were chosen on an operational basis. The early work on the southern section of the North Sea was at less than $200 \mathrm{ft}(61 \mathrm{~m})$, the pipe laying off Aberdeen was at about $300 \mathrm{ft}(92 \mathrm{~m})$, while the recent work off the Shetlands was at a greater depth. Hence distinct operating groups were available for analysis by different working depths and areas.

The measurements of lung volumes were made with the subjects standing upright blowing into a vitalograph. The forced vital capacity was recorded as the maximum expirate (BTPS scale) after the lungs had been filled to their utmost and the greatest voluntary effort was encouraged. The time forced expired volume in one second was also taken from one of these traces. At least three recordings were made at each examination. The largest FVC and $\mathrm{FEV}_{1}$ was taken to be the definitive reading.

The data were coded so that a computer analysis of the measurements could be made. A FORTRAN program was developed to run on an ICL 1905E computer using $32 \mathrm{~K}$ of memory store, the data being retained on magnetic tape. Ranges were selected and signals built into the program to identify individuals outside these ranges.

The means $(\overline{\mathbf{x}})$ and standard deviations (SD) of the whole group for age, height, weight, surface area, number of years' commercial diving experience, and the maximum depth of diving were calculated by the computer. The program arranged the data into subgroups based on age, weight, commercial diving experience, maximum operating depth, percentage predicted $F V C, F_{1}$, and $F E V_{1} / F V C$ percentage so that statistical analysis of the relationship between these subgroups and the total group could be made.

The statistical analysis used was either Student's $t$ test with comparison of $P$ values at $5 \%$ and $1 \%$ levels invoking the null hypothesis or the correlation coefficient between two variables was calculated and the $\mathbf{R}$ value related to the degrees of freedom. Again a value of less than $5 \%$ was regarded as significant.

\section{Results}

The 404 divers were all male and Caucasian in origin; $80 \%$ were natives of the United Kingdom, $15 \%$ American, and $5 \%$ European. Details of their physical characteristics are shown in Table 1.

The age range was 18 to 50 years (mean 29.5) but $67 \%$ were between 25 and 35 years.

The mean height was $176.9 \mathrm{~cm}$ (SD 6.81, range 156 to $196 \mathrm{~cm}$ ). This compares with an average height of $175 \mathrm{~cm}($ SD $6.5 \mathrm{~cm})$ for UK men of a similar age. There is no significant correlation with age but the

Table 1 Morphometric data

\begin{tabular}{|c|c|c|c|c|c|c|c|c|c|}
\hline \multirow{2}{*}{$\begin{array}{l}\text { Age group } \\
\text { (years) }\end{array}$} & \multirow{2}{*}{$\begin{array}{l}\text { No. of } \\
\text { divers }\end{array}$} & \multicolumn{2}{|l|}{ Age } & \multicolumn{2}{|c|}{ Height $(\mathrm{cm})$} & \multicolumn{2}{|c|}{ Weight $(k g)$} & \multicolumn{2}{|c|}{ Surface area-m } \\
\hline & & Mean & $S D$ & Mean & $S D$ & Mean & $S D$ & Mean & $S D$ \\
\hline $\begin{aligned}<20 \\
20-25 \\
25-30 \\
30-35 \\
35-40 \\
40-45 \\
>45\end{aligned}$ & $\begin{array}{r}7 \\
59 \\
158 \\
111 \\
56 \\
8 \\
5\end{array}$ & $\begin{array}{l}18 \cdot 9 \\
22 \cdot 4 \\
27 \cdot 2 \\
31 \cdot 7 \\
36 \cdot 8 \\
42 \cdot 5 \\
47 \cdot 2\end{array}$ & $\begin{array}{l}0 \cdot 38 \\
1 \cdot 43 \\
1 \cdot 40 \\
1.44 \\
1 \cdot 28 \\
1.51 \\
2 \cdot 17\end{array}$ & $\begin{array}{l}178 \cdot 3 \\
177 \cdot 1 \\
177 \cdot 5 \\
176 \cdot 0 \\
177 \cdot 6 \\
171 \cdot 6 \\
176 \cdot 8\end{array}$ & $\begin{array}{l}4 \cdot 19 \\
7 \cdot 42 \\
6 \cdot 47 \\
7 \cdot 34 \\
6 \cdot 31 \\
5 \cdot 50 \\
4 \cdot 82\end{array}$ & $\begin{array}{l}71 \cdot 8 \\
75 \cdot 2 \\
77 \cdot 5 \\
76 \cdot 6 \\
79 \cdot 7 \\
74 \cdot 7 \\
78 \cdot 7\end{array}$ & $\begin{array}{r}6.33 \\
10.54 \\
10.02 \\
10.17 \\
10.52 \\
7.05 \\
5.50\end{array}$ & $\begin{array}{l}1.89 \\
1.92 \\
1.95 \\
1.93 \\
1.97 \\
1.87 \\
1.96\end{array}$ & $\begin{array}{l}0.091 \\
0.154 \\
0.139 \\
0.153 \\
0.146 \\
0.084 \\
0.085\end{array}$ \\
\hline Total & 404 & $29 \cdot 5$ & $5 \cdot 4$ & 176.9 & 6.81 & $77 \cdot 1$ & $10 \cdot 1$ & 1.94 & 0.145 \\
\hline
\end{tabular}




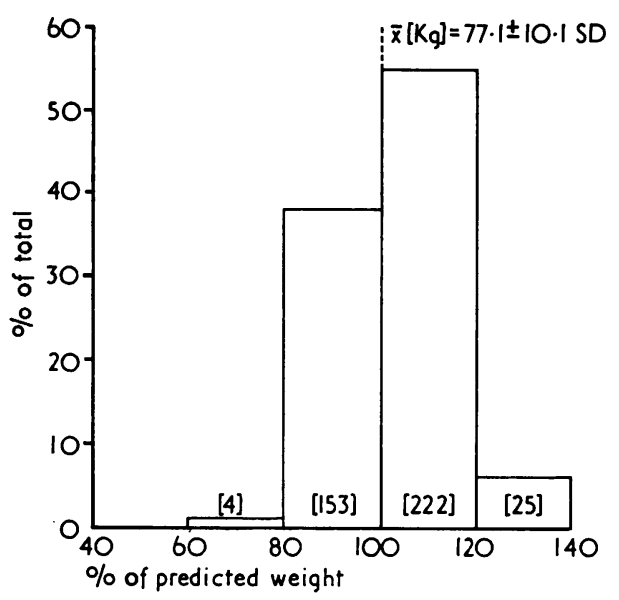

Fig. 1 Distribution of weights

youngest are the tallest.

The mean weight was $77 \cdot 1 \mathrm{~kg}$ (SD $10 \cdot 1$, range 56.4 to $115.5 \mathrm{~kg}$ ). The distribution of the measured weight expressed as a percentage of the predicted weight is shown in Fig. 1. The divers were heavier on average than Western men of similar age and there is a significant correlation $(P<0.01)$ between age and weight: they get heavier as they get older. This is reflected in the calculated mean surface area which also increases with age. Twenty-five men $(6 \%)$ were more than $120 \%$ of their predicted weight and could be considered obese while only four were less than $80 \%$ of their predicted weight.

The distribution of commercial diving experience is shown in Table 2. The mean was $7 \cdot 1$ years (SD 5.2 years). Fifty-five per cent had been diving for more than five years while only $11 \%$ had less than one year's experience. Hence they formed a group of experienced professional operators with few novices. Just over half $(52 \%)$ had worked at a maximum depth of $200 \mathrm{ft}(61 \mathrm{~m})$ while only 23 individuals $(6 \%)$ worked deeper than $500 \mathrm{ft}(153 \mathrm{~m})$. Thus there was a minority who operated at the greatest depths. They were also the heaviest.

Our most interesting finding is in the distribution of FVC (Fig. 2). The mean value was $120.4 \%$ of pre-

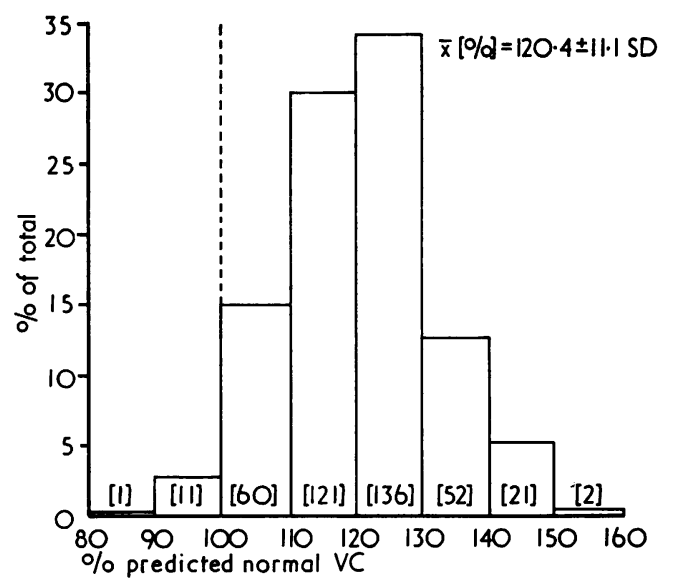

Fig. 2 Distribution of vital capacities

dicted vital capacity while more than half $(52 \%)$ were above the mean. Two individuals were above $150 \%$ but nobody was less than $80 \%$ of the predicted value. The largest absolute vital capacity was at least 7.8 litres BTPS since that was the maximum of our scale. Hence our sample of divers had very large vital capacities and could voluntarily move a large amount of air in and out of their lungs.

The distribution of FEV 1 is shown in Fig. 3. The mean is $117 \%$ of the predicted value with a SD of $12.4 \%$. Again there is an absolute increase in this value compared with that of normal men but the amount is not quite so great as the increase in FVC. Comparing Figs 2 and 3 it is apparent that the two measurements do not superimpose. The FEV 1 shows a wider and less tall distribution of values, and its overall increase is shifted to the left. The changes in vital capacity and air flow are not the same and this is also reflected in the distribution of $\mathrm{FEV}_{1} / \mathrm{FVC} \%$ shown in Fig. 4. The mean value is $81.1 \%$ which is normal for the mean age group of the divers (Bergulund et al., 1963), but a small group (66 men) had values below $75 \%$, and two were in the 50 to $60 \%$ range. This could indicate an abnormal expiratory airflow.

Figure 5 compares the physical characteristics and

Table 2 Diving experience

\begin{tabular}{|c|c|c|c|c|c|c|c|c|c|c|c|}
\hline \multirow{2}{*}{$\begin{array}{l}\text { Groups } \\
\text { No. of years of } \\
\text { commercial diving }\end{array}$} & \multirow{2}{*}{$\begin{array}{l}\text { No. of } \\
\text { divers }\end{array}$} & \multicolumn{2}{|c|}{ Age (years) } & \multicolumn{2}{|c|}{ Weight $(k g)$} & \multicolumn{2}{|c|}{$\%$ predicted FVC } & \multicolumn{2}{|c|}{$\%$ predicted FEV } & \multicolumn{2}{|c|}{$F E V_{1} / F V C \%$} \\
\hline & & Mean & $S D$ & Mean & $S D$ & Mean & $S D$ & Mean & $S D$ & Mean & $S D$ \\
\hline $\begin{array}{rl}<1 & 1-5 \\
& 5-10 \\
> & 10\end{array}$ & $\begin{array}{r}43 \\
141 \\
129 \\
91\end{array}$ & $\begin{array}{l}25 \cdot 6 \\
27 \cdot 3 \\
29 \cdot 6 \\
34 \cdot 5\end{array}$ & $\begin{array}{l}4 \cdot 5 \\
4 \cdot 3 \\
4 \cdot 4 \\
5 \cdot 1\end{array}$ & $\begin{array}{l}73 \cdot 6 \\
76 \cdot 9 \\
77 \cdot 0 \\
79 \cdot 3\end{array}$ & $\begin{array}{r}10 \cdot 3 \\
10 \cdot 3 \\
10 \cdot 1 \\
9 \cdot 5\end{array}$ & $\begin{array}{l}120 \cdot 1 \\
119 \cdot 9 \\
122 \cdot 8 \\
117 \cdot 9\end{array}$ & $\begin{array}{l}11 \cdot 42 \\
10 \cdot 64 \\
11 \cdot 20 \\
11 \cdot 22\end{array}$ & $\begin{array}{l}115 \cdot 6 \\
116 \cdot 8 \\
118 \cdot 6 \\
115 \cdot 1\end{array}$ & $\begin{array}{l}12 \cdot 14 \\
12 \cdot 25 \\
13 \cdot 18 \\
11 \cdot 67\end{array}$ & $\begin{array}{l}81 \cdot 45 \\
81 \cdot 78 \\
80 \cdot 64 \\
80 \cdot 69\end{array}$ & $\begin{array}{l}7 \cdot 74 \\
5 \cdot 97 \\
7 \cdot 53 \\
5 \cdot 34\end{array}$ \\
\hline Total & 404 & $29 \cdot 5$ & $5 \cdot 4$ & $77 \cdot 1$ & $10 \cdot 1$ & $120 \cdot 4$ & $11 \cdot 15$ & $117 \cdot 0$ & $12 \cdot 14$ & $81 \cdot 13$ & $6 \cdot 58$ \\
\hline
\end{tabular}




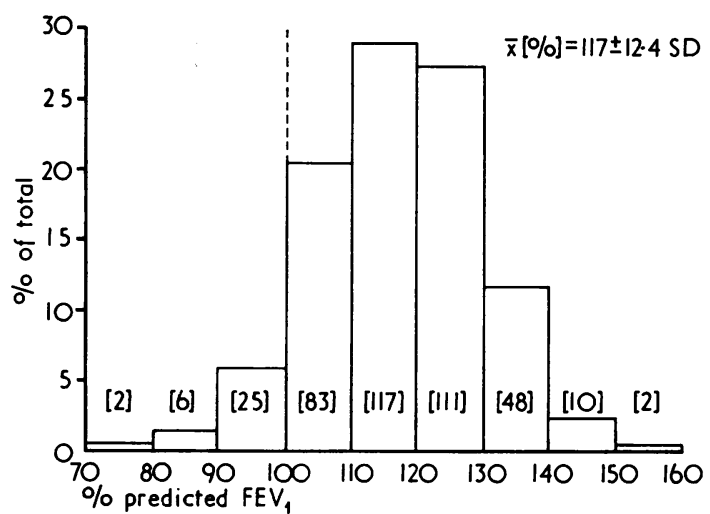

Fig. 3 Distribution of FEV .

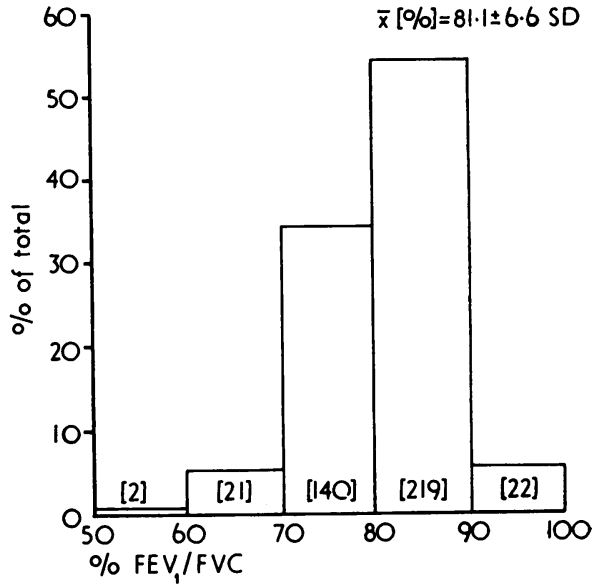

Fig. 4 Distribution of $\% F E V_{1} / F V C$ values.
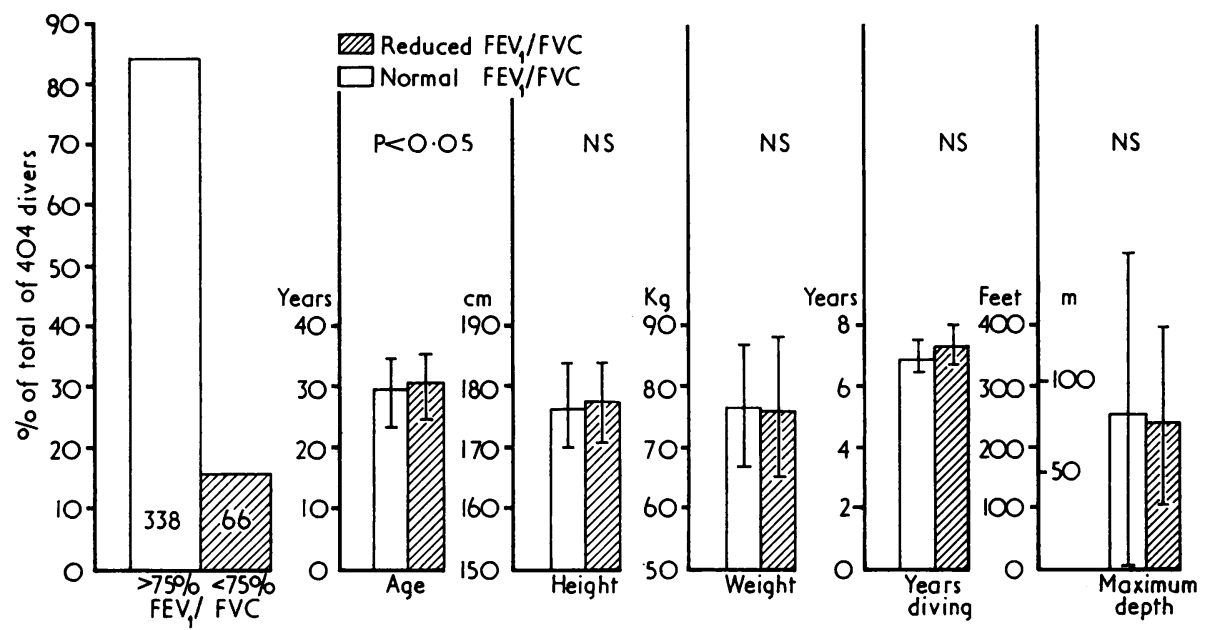

Fig. 5 Comparison of morphometric and diving factors.

Table 3 Maximum depth of dive

\begin{tabular}{|c|c|c|c|c|c|c|c|c|c|c|c|}
\hline \multirow{2}{*}{$\begin{array}{l}\text { Depth ranges } \\
\text { ft }(m)\end{array}$} & \multirow{2}{*}{$\begin{array}{l}\text { No. of } \\
\text { divers }\end{array}$} & \multicolumn{2}{|c|}{ Age (years) } & \multicolumn{2}{|c|}{ Weight (kg) } & \multicolumn{2}{|c|}{$\%$ predicted FVC } & \multicolumn{2}{|c|}{$\%$ predicted FEV $V_{1}$} & \multicolumn{2}{|c|}{$F E V_{1} / F V C \%$} \\
\hline & & Mean & $S D$ & Mean & $S D$ & Mean & $S D$ & Mean & $S D$ & Mean & $S D$ \\
\hline $\begin{array}{l}0-200 \\
(60.9)\end{array}$ & 209 & $28 \cdot 4$ & $5 \cdot 1$ & $75 \cdot 2$ & $10 \cdot 0$ & $120 \cdot 2$ & $11 \cdot 1$ & $116 \cdot 1$ & $12 \cdot 1$ & $81 \cdot 1$ & $6 \cdot 58$ \\
\hline $\begin{array}{l}200-300 \\
(60 \cdot 9-91 \cdot 5)\end{array}$ & 94 & $29 \cdot 4$ & $5 \cdot 7$ & $78 \cdot 7$ & $10 \cdot 2$ & $120 \cdot 1$ & $10 \cdot 2$ & $117 \cdot 8$ & $11 \cdot 7$ & $81 \cdot 9$ & $5 \cdot 88$ \\
\hline $\begin{array}{l}300-500 \\
(91 \cdot 5-152 \cdot 4)\end{array}$ & 78 & $31 \cdot 7$ & $5 \cdot 2$ & $78 \cdot 8$ & $10 \cdot 2$ & $120 \cdot 7$ & $12 \cdot 4$ & $116 \cdot 7$ & $14 \cdot 1$ & $80 \cdot 5$ & $7 \cdot 39$ \\
\hline $\begin{array}{l}>500 \\
(152.4)\end{array}$ & 23 & $32 \cdot 0$ & $5 \cdot 1$ & $82 \cdot 6$ & 6.9 & $123 \cdot 2$ & 11.5 & 120.5 & $12 \cdot 8$ & $81 \cdot 3$ & 6.52 \\
\hline $\begin{array}{l}0-1100 \\
(361)\end{array}$ & 404 & $29 \cdot 5$ & $5 \cdot 4$ & $77 \cdot 1$ & $10 \cdot 1$ & $120 \cdot 4$ & $11 \cdot 15$ & $117 \cdot 0$ & $12 \cdot 14$ & $81 \cdot 13$ & 6.58 \\
\hline
\end{tabular}


diving experience of divers having an $\mathrm{FEV}_{1} / \mathrm{FVC}$ ratio above $75 \%$ with those below $75 \%$. The only statistically significant difference between the two groups is that of age. Those with a lower ratio were older, as one would expect. There is no relationship between the number of years employed as a commercial diver and maximum operating depth.

Table 2 also shows the association between the commercial diving experience and ventilatory function of the divers. Even those with less than one year's diving experience had an increased FVC but the largest increase was in those who had been diving for between 5 and 10 years. Men with more than 10 years' experience had a decrease in mean FVC but they were also the heaviest, being $\_\mathrm{kg}$ above the group mean.

Table 3 shows the relationship between the operating depths of the divers and their ventilatory lung volumes. The most important finding is that divers who go deepest $(>500 \mathrm{ft} / 153 \mathrm{~m}$ ) have the largest vital capacities. Since all our measurements were made on the same machine this is likely to be a real increase. The $F E V_{1}$ and $F E V_{1} / F V C$ ratio also reflect this finding. These divers are also the heaviest, being $5 \mathrm{~kg}$ above the group mean.

\section{Discussion}

Information on the physical characteristics and ventilatory function of commercial divers has not been reported although much is known about naval divers under experimental conditions (Lamphier, 1975). Group discipline, operational supervision, and medical care of these two groups are different although many commercial divers obtain their basic diving training in naval service. We have analysed the data obtained during the routine medical examination of 404 commercial divers employed by companies operating in gas or oil exploration in the North Sea. The men were in the age range 18 to 50 years with a mean age of 29 years, $67 \%$ being within the 25 to 35 years range. This suggests that a combination of fitness and experience is a characteristic of the group.

Our divers were not wearing shoes when they were weighed, but the predicted value does include shoe weight. We did not apply a correction factor and as our data are presented as a percentage of the predicted value, it will underestimate the incidence of obesity in the group. It is a personal observation that operational divers are slimmer than when examined on shore so that if the time of year of the particular examination was at the end of a vacation it is likely that the individual would be heavier than when working. Nevertheless, only a minority were considered to be overweight but it is not known whether the additional weight was due to fat or increased lean body mass. Since there is a real physical element in the work it seems likely that extra muscular development had taken place. Measurements of skinfold thickness are now being made to answer this question.

Much of the work involved in oil or gas exploration is visual inspection or coupling of lifting gear underwater. Sometimes considerable physical strength is required when using compression tools on concrete structures or supporting jet cleaning guns. Similar intense effort has been shown in astronauts working outside space capsules where they also are weightless and any effort has to be counterbalanced by physical work in the reverse direction. The increase in average weight of our group with age is most likely to be related to normal ageing and not to environmental factors. The excess weight of men aged 35 to 40 years is greater than that of men aged 20 to 25 years. As a similar number of divers are analysed in each group and the average height is the same, this indicates that the older men have become more muscular or have gained more fat than the overall average. That five men over 45 years are lighter than the 35 to 40-year group suggests that the latter are at the peak of their physical development brought about by age and mode of life.

The surface area measurements calculated from age, height, and weight show that the mean area is larger than the expected value for men of the same age. This follows from their increased average weight. The 35 to 40-year age group have the largest value. Since it is known that the heat exchange area, oxygen uptake and carbon dioxide output, and metabolism are related to surface area it would be useful to know the distribution of this measurement in a sample population. We did not directly measure surface area but our group were normal on physical examination.

The most interesting finding in this study is the large size of the mean vital capacity, which was 6.2 litres $(120 \%$ of the predicted value), and some individuals could voluntarily expel 7.8 litres of air from their lungs. Some dry spirometers may be in error up to $10 \%$ full scale deflection, but the particular instrument used has been calibrated and found to have an error of between 1 and $2 \%$ over the $7 \cdot 8$ litre range. We consider our measurements to be accurate and to reflect directly the amount of air voluntarily forced out of the lungs. Other occupational groups involved in underwater work also develop large vital capacities. The best known are the ama pearl divers who were intensively studied by Hong et al. (1963) and were shown to have vital 
capacities $15 \%$ above average. These divers hold their breath underwater and dive to only 15 to $20 \mathrm{ft}$ ( 5 to $7 \mathrm{~m}$ ) although some go deeper using weights to help them descend. Nevertheless they must retain an exceptional degree of muscular control over their breathing and use their respiratory muscles much more than most people. A relevant study is that on diving tank instructors reported by Carey et al. (1956) who showed that men who worked regularly underwater developed large vital capacities, and that this volume increased at the end of a period of underwater work. Vital capacities larger than predicted have also been found in competitive oarsmen, track athletes, and cyclists. We suggest that four factors are responsible for commercial divers showing the largest FVC. 1. Our group had been working at depths to $1100 \mathrm{ft}(340 \mathrm{~m})$ and the average length of experience was $7 \cdot 1$ years, hence the stimulus to develop larger respiratory muscles was greater. 2 . The density of gas increases with pressure and it is more difficult to ventilate the lung (Maio and Fahri, 1967). At four atmospheres the maximum peak expiratory airflow in exercising subjects in a pressure tank was 266 litres/min while at 15 atmospheres, a depth common to our divers, it was 140 litres/min (Vail, 1971). Most divers have been subjected to frequent high density gas breathing and often worked manually at the same time. Only caisson workers experience similar circumstances but they usually only work in two to three atmospheres absolute and do not breathe through valve systems. It is also known that as gas pressure increases there is a reduction in expiratory airflow indices but that vital capacity and lung compliance are unaltered. The mechanism of this increase in airways resistance is related to the greater density of the gas and is particularly marked when flow is turbulent during the increased ventilation caused by physical work. 3. The valve system of the breathing apparatus increases the work of respiration in divers. All valve systems increase airflow resistance, some systems more than others. The free swimming diver has to inspire against the spring valve which increases his respiratory effort. Some systems are free flowing while others operate on demand only. Even traditional helmeted divers had to activate valve mechanisms. 4. The modern diver wears a rubberised wet suit which fits closely round the chest. Work must be done to stretch this suit hence the respiratory muscles have an additional burden and stimulus to hypertrophy when stress is repeated almost daily.

We suggest that these four factors combine to cause hypertrophy of the thoracic wall and diaphragm muscles. To support these views our data show that the divers who go deepest have the largest vital capacities. We have not measured the residual volume of our subjects so we do not know their total lung capacities but in similar occupation groups, the residual volume has been found to be normal and the total lung capacity increased (Song et al., 1963). We think our divers would fit into the same pattern. This means the diaphragmatic excursion and/or the thoracic wall expand more than normal. Since the diver usually begins training in his late adolescence and early twenties it is at a time when these tissues can stretch.

The structure of lung parenchyma must also change if the lung volume is increased. More lung units could develop but this is unlikely in the age range studied.

The $F E V_{1}$ is increased but not quite to the same extent as the FVC, indicating that most of our men have normal expiratory airflows. Only three have an absolute value below $83 \%$ of the predicted value and they could have mild airways narrowing produced by early lung disease, but they have no respiratory symptoms or other abnormal physical findings. There is a good, almost symmetrical, scatter of individual measurements in the histogram but it appears that the whole group is shifted slightly to the left compared with the graph of FVC. The increase in FEV 1 is not so great as the increase in FVC. This might be an artefact produced by using a dry spirometer but the machine has been shown to have a linear response over the measured range. The subjects appeared to give maximum effort, resulting in a true difference in the two measurements. The FEV 1 is dependent on several variables such as airways resistance, lung recoil pressure, and respiratory muscular effort. The last two factors have been discussed in relation to the FVC and we think they are normal. Changes in airways resistance remain important factors. The total airways resistance depends on the number of airways present, their length, and their combined crosssectional areas. There has been an increase in the size of the lungs but it is unlikely that they have developed extra airways, it is more likely that the increase in length and/or in total cross-sectional area is not quite as great as the increase in lung volume. This would explain the different distribution patterns of FVC and FEV 1 .

$A$ reduced $\mathrm{FEV}_{1} / \mathrm{FVC}$ ratio is associated with expiratory obstruction. While low values occur in advanced chronic bronchitis it is less easy to decide where the normal ends and the abnormal begins. This division is even more difficult where the FVC is increased above normal. If the reported normal (Cotes, 1975) is taken and a standard deviation allowed then our divers can be divided into those above and below $75 \%$. Age was the only significant difference in the two groups, those with a lower ratio being older. This may simply reflect the decrease in 
$\mathrm{FEV}_{1} / \mathrm{FVC}$ with age although in absolute terms the mean age was $29 \cdot 2$ years for those above $75 \%$ and $30 \cdot 2$ years for the under $75 \%$ group, while the predicted $F E V_{1} / F V C$ ratio was almost the same. It might also mean that those with a lower ratio have chronic bronchitis although none of our divers admitted to the regular production of sputum. We do not know the smoking histories of our subjects but it is thought that a majority do smoke.

Further information on this important finding is required since it suggests a possible mechanism for respiratory distress developing when ascending from depth. Chronic bronchitis does not affect all the airways equally, and some will be more obstructed than others. Expansion of alveolar gas occurs as divers ascend from depth, so that local areas of hyperinflation could occur. In some circumstances a gas pocket could form and rupture into the pleural cavity to produce a pneumothorax. This has occurred in submarine escape training (Liebow et al., 1959). More detailed investigation of the expiratory airflow pattern of divers is required to answer this problem.

Our data do not show any relationship between the presence of a reduced $F E V_{1} / F V C$ ratio and factors relating to the diving environment. Neither the duration of employment as a commercial diver nor the maximum depth of operation appears to influence it. These are crude indices of working conditions but at least they are factual and deserve analysis. Similarly the physical characteristics of the men in the two groups show no significant difference. It is often asked whether working as a diver for several years has a detrimental effect on lung function. We have not yet gathered sufficient longitudinal data on individual divers to answer this question but our data on the group as a whole show that there has been no abnormal deterioration in lung function in those who have been diving for several years. The small reduction in mean vital capacities of those who have been diving for more than 10 years could occur as the result of their increased body weight. The reduction in absolute terms is less than $500 \mathrm{ml}$ and they still have forced vital capacities larger than the normal population.

We thank the staff of the Chest Unit, Miss A. P. Rowe for typing the manuscript, Miss C. Rea of the
Library, the Department of Ergometrics at Loughborough University, and the Society of Actuaries of Great Britain for providing normal data. We also thank the nursing staff at Great Yarmouth. Mrs S. A. Spooner, for secretarial assistance, and the divers and diving companies for their cooperation in making this study possible.

\section{References}

Bergulund, E., Birath, G., Bjure, J., Grimby, G., Kjellmer, I., Sandquist, L., and Söderholm, B. (1963). Spirometric studies in normal subjects. 1. Forced expirograms in subjects between 7 and 70 years of age. Acta medica Scandinavica, 173, 185-192.

British Medical Journal (1976). Medicine in the seventiesThe North Sea. British Medical Journal, 1, 705-706.

Carey, C. R., Schaefer, K. E., and Alvis, H. J. (1956). Effect of skin diving on lung volumes. Journal of Applied Physio$\log y, 8,519-523$.

Cotes, J. E. (1975). In Lung Function, 3rd edition, p. 364. Blackwell: Oxford.

Documenta Geigy (1970). Scientific Tables, 7th edition, p. 711. Geigy: Basle.

Dubois, D., and Dubois, E. F. (1915). The measurement of surface area of man. Archives of Internal Medicine, 15, 868.881 .

Hong, S. K., Rahn, H., Kang, D. H., Song, S. H., and Kang, B. S. (1963). Diving pattern, lung volumes and alveoli gas of the Korean diving woman (ama). Journal of Applied Physiology, 18, 457-465.

Kory, R. C., Callahan, R., Bonen, H. G., and Syner, J. C. (1961). The Veterans Administration-Arm co-operative study on pulmonary function. 1. Clinical spirometry in normal men. American Journal of Medicine, 30, 243-258.

Lamphier, E. H. (1975). In The Physiology and Medicine of Diving and Compressed Air Work, 2nd edition. Edited by P. B. Bennett and D. H. Elliott. Ballière Tindall: London.

Liebow, A. A., Stark, J. E., Vogel, J., and Schaefer, K. E. (1959). Intrapulmonary trapping in submarine escape training casualties. United States Armed Forces Medical Journal, 10, 265-267.

Maio, D. A., and Fahri, L. E. (1967). Effect of gas density on the mechanics of breathing. Journal of Applied Physio$\log y, 23,687-692$.

Montegriffo, V. M. E. (1968). Height and weight of a United Kingdom adult population with a review of arthropometric literature. Annals of Human Genetics, 31, 389-399.

Scottish Council (1975). British Medical Association Report of the Working Party on the Medical Implications of Oil Related Industry BMA: London.

Song, S. H., Kang, D. N., Kang, B. S., and Hong, S. K. (1963). Lung volumes and ventilatory responses to high $\mathrm{CO}_{2}$ and low $\mathrm{O}_{2}$ in the ama. Journal of Applied Physiology, 18, 466-469.

Vail, E. G. (1971). Hyperbaric respiratory mechanics. Aerospace Medicine, 42, 975-979. 